8th International Conference on Physical and Numerical Simulation of Materials Processing (ICPNS)

14-17 October 2016

Seattle, Washington | Hosted by Purdue University

SESSION 6: LIGHT ALLOYS, MARITIME HALL

Co-Chairs: Jong Ning Aoh, National Chung Cheng University; Zuyan Liu, Harbin Institute of Technology

SUNDAY, OCTOBER 16, 2016

\title{
Simulation of the bite condition of AZ31 sheet rolling
}

\author{
Zuyan Liu, Harbin Institute of Technology
}

\begin{abstract}
Sheet rolling is a simple plastic deformation, of which there are many formulas to describe its bite condition; however, there is no rigorous theoretical analysis and result, and the applying ranges of these formulas are limited. Although the bite condition is not an important problem in engineering or academy, it is really a term influenced by many factors and it is difficult, maybe impossible to be expressed by an equation. In this paper, by finite element software, the bite condition or the critical friction factor under different thickness of AZ31 sheet, rolling reduction, sheet temperature, and roller temperature are calculated, and with large result data, the change regulation of the bite condition appears which is shown in a color brick model. This example shows that, avoiding rigorous theoretical analysis, a complex situation can be numerically illustrated well using finite element software.
\end{abstract}

KEYWORDS: bite condition, numerical simulation, sheet rolling, AZ31 